Article

\title{
Sustainable FRP-Confined Symmetric Concrete Structures: An Application Experimental and Numerical Validation Process for Reference Data
}

\author{
Ali Raza ${ }^{1}$, , Syyed Adnan Raheel Shah ${ }^{1, *}$, Ahsan Rehman Khan ${ }^{2}$, Muhammad Asif Aslam ${ }^{3}$, \\ Tanveer Ahmed Khan ${ }^{3, *} \mathbb{0}$, Kinza Arshad ${ }^{1}$, Sabahat Hussan ${ }^{4}$, Asad Sultan ${ }^{5}$, Gullnaz Shahzadi ${ }^{6}$ \\ and Muhammad Waseem ${ }^{7}$ \\ 1 Department of Civil Engineering, Pakistan Institute of Engineering and Technology, Multan 66000, Pakistan; \\ araza4846@gmail.com (A.R.); kinzaarshad@piet.edu.pk (K.A.) \\ 2 Department of Civil Engineering, NFC- Institute of Engineering and Technology, Multan 66000, Pakistan; \\ ahsanrehman@nfciet.edu.pk \\ 3 University College of Engineering \& Technology, Bahauddin Zakariya University, Multan 66000, Pakistan; \\ masifaslam@bzu.edu.pk \\ 4 Department of Civil Engineering, HITEC University, Taxila 47080, Pakistan; sabahat.hasan@hitecuni.edu.pk \\ 5 Department of Civil Engineering, University of Sargodha, Sargodha 40100, Pakistan; asad.sultan@uos.edu.pk \\ 6 Department of Mechanical Engineering, École de Technologie Supérieure, ÉTS, Montreal, QC H3C 1K3, \\ Canada; gullnaz.shahzadi.1@ens.etsmtl.ca \\ 7 Bayreuth Centre for Ecology and Environmental Research, University of Bayreuth, 95440 Bayreuth, \\ Germany; muhammad.waseem@uni-bayreuth.de \\ * Correspondence: syyed.adnanraheelshah@uhasselt.be (S.A.R.S.); tanveerkhan@bzu.edu.pk (T.A.K.); \\ Tel.: +923007914248 (S.A.R.S.)
}

Received: 10 December 2019; Accepted: 28 December 2019; Published: 2 January 2020

\begin{abstract}
The use of fiber-reinforced polymer (FRP) jackets as external confinement is becoming popular, especially in seismic areas, because of its ability to enhance the strength and ductility of reinforced concrete to perform as a sustainable symmetric structural member. Therefore, various researchers have worked out for the prediction of strength and strain models of FRP-confined concrete. This study presents the improved strain models for the FRP confined cylindrical concrete members. Different previously proposed models of axial strain of FRP-confined concrete were evaluated based on a large database of 678 specimens from previous experiments and an improved model was proposed using the general regression analysis technique. Furthermore, the proposed model was validated using the previous experimental work of FRP-wrapped concrete cylinders and their finite elements analysis (FEA) using the ABAQUS software. The accuracy of the proposed strain model was quite satisfactory in comparison with the previous experimental and FEA results of the present study. Moreover, the proposed empirical strain model was used for the parametric study to investigate the effect of different geometric and material parameters such as the compressive strength of unconfined concrete, diameter of the cylinder, elastic modulus and thickness of the FRP layers, on the axial strain of FRP-wrapped cylinders. A close agreement among the proposed strain models and experimental outputs was observed. This study will help in understanding the behavior of sustainable FRP-confined symmetric concrete members.
\end{abstract}

Keywords: symmetry; FRPs; confined concrete; strain model; sustainability

\section{Introduction}

Recently, in densely populated earthquake regions, advanced FRPs are being increasingly used for the urgent retrofitting, rehabilitation and strengthening of damaged structures because of the 
advantages of increasing the ductility and strength of reinforced concrete (RC) columns wrapped with externally FRPs confinements. The increase in axial strength and strain of RC columns is the main reason for the attraction of the use of fiber-reinforced polymers (FRP) confinements. The repairing, strengthening and ductility enhancement of RC compression members is one of the most popular applications of the FRP composites in both corrosive and seismic environments [1]. The advantages of the FRP composites include corrosion resistance, lightweight, high strength to weight ratio, durability, chemical resistance, dimensional stability and electromagnetically neutral [2]. The factors affecting the FRP confinement are elastic modulus of FRP $\left(E_{f}\right)$, thickness of FRPs $(n t)$, angle of orientation of FRP wraps, and unconfined strength of concrete material $\left(f_{c o}^{\prime}\right)$ [3]. Nowadays, FRP confinement has become an advanced technology for increasing the efficiency and strength of structural concrete [4]. FRPs are preferred over conventional steel jacketing due to their easy handling, slight disturbance of concrete members, easy installation and less time for construction [5].

The strengthening technique, which is influenced by the orientation, geometry, and shape of the concrete member, is also very important for increasing the capacity of structural members $[6,7]$. The strength of confined concrete is reduced when the fibers are used at an angle between the longitudinal and transverse directions of concrete members [8]. The damaged concrete structures due to earthquakes lose their serviceability and strength and thus, they need retrofitting and rehabilitation to enhance strength and ductility [9]. The high corrosion resistance properties of FRPs make them suitable for being used in marine and coastal structures [10]. The applications of FRPs are not limited to concrete building members but also in the bridge piers to enhance their strength by lateral confinement [11-13]. In fact, the increase in strength and ductility of concrete members after FRPs wrapping is due to the confinement and prevention of the lateral expansion of concrete material. This effect of confinement is more dominant in case of triaxial state because the concrete would be subjected to multiaxial loads when FRP wrapping resists lateral expansion [14].

Various researches have been performed in the literature for predicting the axial strain $\left(\varepsilon_{c c}^{\prime}\right)$ of externally confined concrete members based on different techniques [15-22]. Based on the concept of the linear relationship between the confinement pressure and strain, the strain models were proposed [17,22]. Lam and Teng [20] proposed the strain model based on the concept of dilation behavior and volume strain of concrete. In addition, the strain model proposed by Mander et al. [16] uses the concept of the energy balance method according to which the additional strain energy of confined concrete is equal to energy required to break the FRP hoops. It was observed from the literature that most of the studies focused on the predictions of axial compressive strength of confined concrete members but, fewer models were proposed for axial compressive strain. For a designer, the enhancement of axial compressive strain is very important for concrete structural elements after addition of the FRPs. The previously proposed empirical models poorly predict the strains of confined concrete members as compared with the experimental predictions [23]. Moreover, the mean absolute error (MAE) of prediction of confined concrete strength is less than $20 \%$ while, that for confined concrete strains ranges from $35 \%$ to $250 \%$. Thus, the literature shows excellent performance for the strength models but not good for the predictions of corresponding strains. Moreover, the previously proposed strain models for FRP confined were established using small experimental databases, simple spreadsheets, curve fitting techniques with limited curve fitting variables and functions in which researchers could not cover all the interrelations and combinations of the parameters. It had been targeted to determine the confinement effects of the FRP wrapping on different physical and mechanical properties of concrete members such as compressive strength, flexural strength and tensile strength $[18,24]$. However, a further research with a large experimental database is needed to propose a more general strain model for confined concrete.

Based on the experimental work, analytical models for the axial strain of confined concrete compression members were proposed [15-21] which played an important role in predicting the approximate analysis results, but they do not fully explore the fundamental behavior and interaction mechanisms between confinement materials and the concrete. To overwhelm the inadequacy of these 
proposed models for confined concrete, one can move towards the three-dimensional finite elements analysis (FEA) with all the deficiencies of analytical models explicitly represented. In comparison with the experiments, FEA simulations can save the cost and time by developing the numerical models which predict the complex damage behavior accurately [25]. To speed up the simulations and simplify the FEA model, it is essential to consider some assumptions, but it is also important to follow the conditions to be applied in experiments. There should be a balance in model complexity, element types and mesh sizes to enhance the precision of the results and to reduce the time of calculation work. Thus, numerical methods with strong background knowledge of FEA are more efficient and convenient tools to be used for engineering research [26]. The structural performance of FRP-confined concrete was accurately predicted by FEA models [27-31].

In the current research, regression analysis was employed to study the strain prediction of the FRP-confined concrete. Previously proposed strain models for FRP-confined concrete compression members were developed using small data points giving larger deviations but presently proposed models were proposed using a large experimental database of axial strains of 678 concrete members externally confined with FRPs that were collected from previous researches and evaluated based on some statistical indices such as coefficient of determination $\left(R^{2}\right)$ and root mean square error (RMSE) using the previously proposed strain models. Furthermore, the validation of the empirical model was performed by a previous experimental work of 18 FRP confined concrete cylinders and their nonlinear finite element analysis (FEA). An extensive parametric study was performed using the proposed empirical strain model to investigate the sensitivity of various parameters of confined concrete. The significance of the present study is that the proposed models can accurately capture the axial strain behavior of confined concrete which is helpful for the analysis and design of confined concrete members and for the implementation of confined concrete in construction industry.

\section{FRP Confinement Mechanism}

In literature, the proposed strain models contain some common variables such as confinement stiffness ratio $\rho_{\mathrm{k}}$, strain ratio $\rho_{\varepsilon}$, hoop rupture strain of fibers $\varepsilon_{\mathrm{h}, \text { rup }}$ and maximum confinement stress $f_{1}$. The relations for $\rho_{\mathrm{k}}$ and $\rho_{\varepsilon}$ were presented by [32].

$$
\begin{gathered}
\rho_{\varepsilon}=\frac{\varepsilon_{\mathrm{h}, \mathrm{rup}}}{\varepsilon_{\mathrm{co}}} \\
\rho_{\mathrm{k}}=\frac{2 \mathrm{E}_{\mathrm{f}} \mathrm{t}}{\left(\frac{\mathrm{f}_{\mathrm{co}}^{\prime}}{\varepsilon_{\mathrm{co}}}\right) \mathrm{D}}
\end{gathered}
$$

where ' $t$ ' is the thickness of FRP sheets, ' $E_{\mathrm{f}}$ ' is the elastic modulus of confinement sheets in the transverse direction of specimen, ' $f_{\mathrm{co}}^{\prime}$ ' is the unconfined strength of concrete and ' $\varepsilon_{\mathrm{co}}$ ' is the ultimate compressive strain that corresponds to the compressive strength of concrete. Figure 1 represents the confinement stresses due to FRP-jackets with a hoop diameter D. The relationship between the maximum confinement stress and different variables as shown in Figure 1 can be represented by Equation (3). The hoop rupture strain can be represented by Equation (4) [33].

$$
\begin{gathered}
\mathrm{f}_{1}=\rho_{\varepsilon} \rho_{\mathrm{k}} \mathrm{f}_{\mathrm{co}}^{\prime}=\frac{2 \mathrm{E}_{\mathrm{f}} \varepsilon_{\mathrm{h}, \text { rup }} \mathrm{t}}{\mathrm{D}} \\
\varepsilon_{\mathrm{h}, \text { rup }}=\frac{\varepsilon_{\mathrm{f}}}{\mathrm{f}_{\mathrm{co}}^{\prime 0.125}}
\end{gathered}
$$

where, $\varepsilon_{\mathrm{f}}$ is the maximum tensile strain of fibers. 


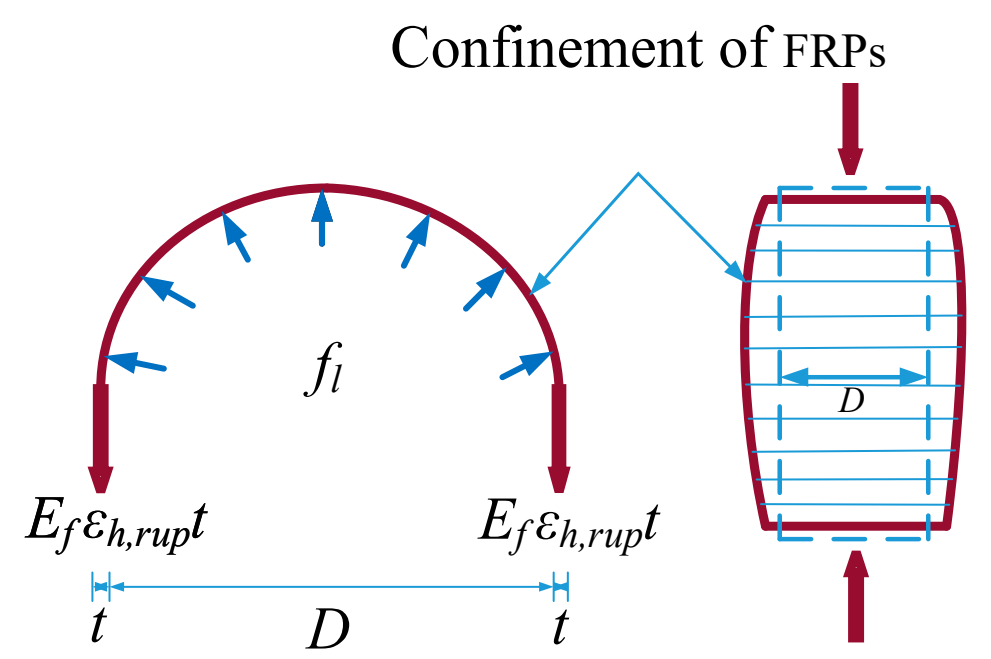

Figure 1. Confinement mechanics of fiber-reinforced polymer (FRP) sheets.

First of all, the strain model for FRP confined concrete was proposed by [15]. According to this model, the ultimate strain increases with the circumferential stiffness of confined concrete. Mander et al. [16] gave the strain model for concrete confined with steel stirrups which was adopted by ACI 440-2R-02 [34] for design guidelines of FRP confined concrete. In strain model proposed by [17], it was assumed that the FRP confinement reaches to its maximum tensile strength in hoop direction which is not possible. Samaan et al. [18] developed the strain model for FRP-tubed confined concrete and concluded that the effective hoop strain at rupture is less than that obtained from uniaxial tensile tests. The first strain model which includes the actual rupture strain of FRPs $\left(\varepsilon_{\mathrm{h}, \text { rup }}\right)$ was developed by [19]. Lam and Teng [20] proposed the strain model for FRP confined concrete based on a small experimental database of 76 sample points by taking into consideration the actual failure strain of wraps. Later on, this model was refined by Teng et al. [21] based on 18 tested specimens which gave close agreement with the experimental results of axial compressive strains. Table 1 represents the strain models used in the present study for the evaluation of currently developed database and to select a general form the currently proposed strain model.

Table 1. Previous strain models for confined concrete.

\begin{tabular}{lll}
\hline \multicolumn{1}{c}{ Model } & \multicolumn{1}{c}{ Expression for Strain of Confined Concrete } \\
\hline Fardis and Khalili [15] model & $\varepsilon_{c c}=0.002+0.001 \frac{E_{f} t}{D f_{c o}^{\prime}}$ & $(7)$ \\
Mander et al. [16] model & $\frac{\varepsilon_{c c}}{\varepsilon_{c o}}=1+5\left(\frac{f_{c c}^{\prime}}{f_{c o}^{\prime}}-1\right)$ & $(8)$ \\
Karbhari and Gao [17] model & $\varepsilon_{c c}=\varepsilon_{c o}+0.01 \frac{f_{l}}{f_{c o}^{\prime}}$ & $(9)$ \\
Samaan et al. [18] model & $\varepsilon_{c c}=\frac{f_{c c}^{\prime}-f_{o}}{E_{2}}$ & \\
& where $f_{o} \stackrel{1}{=} 0.872 f_{c o}^{\prime}+0.371 f_{l}+6.258$ \\
Toutanji [19] model & and $E_{2}=245.61 f_{c o}^{\prime 0.2}+1.3456 \frac{E_{f} t}{D_{c}^{\prime}}$ \\
Lam and Teng [20] model & $\frac{\varepsilon_{c c}}{\varepsilon_{c o}}=1+\left(310.57 \varepsilon_{h, r u p}+1.90\right)\left(\frac{f_{c c}^{\prime c}}{f_{c o}^{\prime}}-1\right)$ \\
Teng et al. [21] model & $\frac{\varepsilon_{c c}}{\varepsilon_{c o}}=1.75+12 \rho_{k} \rho_{\varepsilon}^{1.45}$ \\
\hline
\end{tabular}

\section{Materials and Methods}

\subsection{Formulation of Analytical Models}

In the present study, a design-oriented strain model was proposed based on a large experimental database of 678 confined concrete cylinders (S2 datasheet). The statistical information of the database is shown in Table 2. The whole process was performed using curve fitting technique giving the best 
fit after minimizing some statistical parameters such as $\mathrm{R}^{2}$, RMSE, and the sum of squared errors (SSE) between the predictions of previous models and experimental values. The evaluations of strain models given by Fardis and Khalili [15], Mander et al. [16], Karbhari and Gao [17], Samaan et al. [18], Toutanji [19], Lam and Teng [20] and Teng et al. [21] were performed using the collected database. The models selected for evaluation have wider use in literature. The statistical parameters $R^{2}$ and RMSE are represented by Equations (12) and (13), respectively.

$$
\begin{gathered}
R^{2}=\left(\frac{n\left(\sum x y\right)-\left(\sum x\right)\left(\sum y\right)}{\sqrt{\left[n \sum x^{2}-\left(\sum x\right)^{2}\right]\left[n \sum y^{2}-\left(\sum y\right)^{2}\right.}}\right)^{2} \\
R M S E=\sqrt{\frac{\sum(x-y)^{2}}{n}}
\end{gathered}
$$

Table 2. Statistical information of collected database.

\begin{tabular}{lccccccc}
\hline & $\boldsymbol{D}(\mathbf{m m})$ & $\boldsymbol{H}(\mathbf{m m})$ & $\boldsymbol{n t}(\mathbf{m m})$ & $\boldsymbol{E s}(\mathbf{G P a})$ & $\left.\mathbf{f}_{\mathbf{c o}}^{\prime} \mathbf{( M P a}\right)$ & $\boldsymbol{\varepsilon}_{\mathbf{c o}}(\mathbf{\%})$ & $\boldsymbol{\varepsilon}_{\mathbf{c c}}(\mathbf{\%})$ \\
\hline Min & 51.00 & 102.00 & 0.09 & 10.00 & 12.41 & 0.17 & 0.33 \\
Max & 406.00 & 812.00 & 5.90 & 663.00 & 188.20 & 1.53 & 4.62 \\
Mean & 153.70 & 307.57 & 0.92 & 174.59 & 43.52 & 0.27 & 1.60 \\
+ S.D & 43.91 & 87.83 & 1.06 & 120.06 & 22.31 & 0.14 & 0.82 \\
* COV & 0.29 & 0.29 & 1.16 & 0.69 & 0.52 & 0.52 & 0.52 \\
\hline
\end{tabular}

+ Standard Deviation. * Coefficient of Variance.

Where $\mathrm{n}$ is number of data points; $\mathrm{x}$ is the experimental value and $\mathrm{y}$ is the predicted value of confined concrete strain. The value of parameter RMSE varies from zero to one giving a perfect prediction at zero. Similarly, the value of parameter $R^{2}$ also varies from zero to one; one shows a perfect correlation and zero represents that there is no correlation between experimental and predicted values of strains. The difference between experimental and predicted values was taken as error and SSE was minimized to achieve the best fit. A smaller value of SSE shows a tight fit of the empirical model to the experimental data. The performances of the previously proposed confined concrete strain models with $R^{2}$ and RMSE were represented in Figure 2.
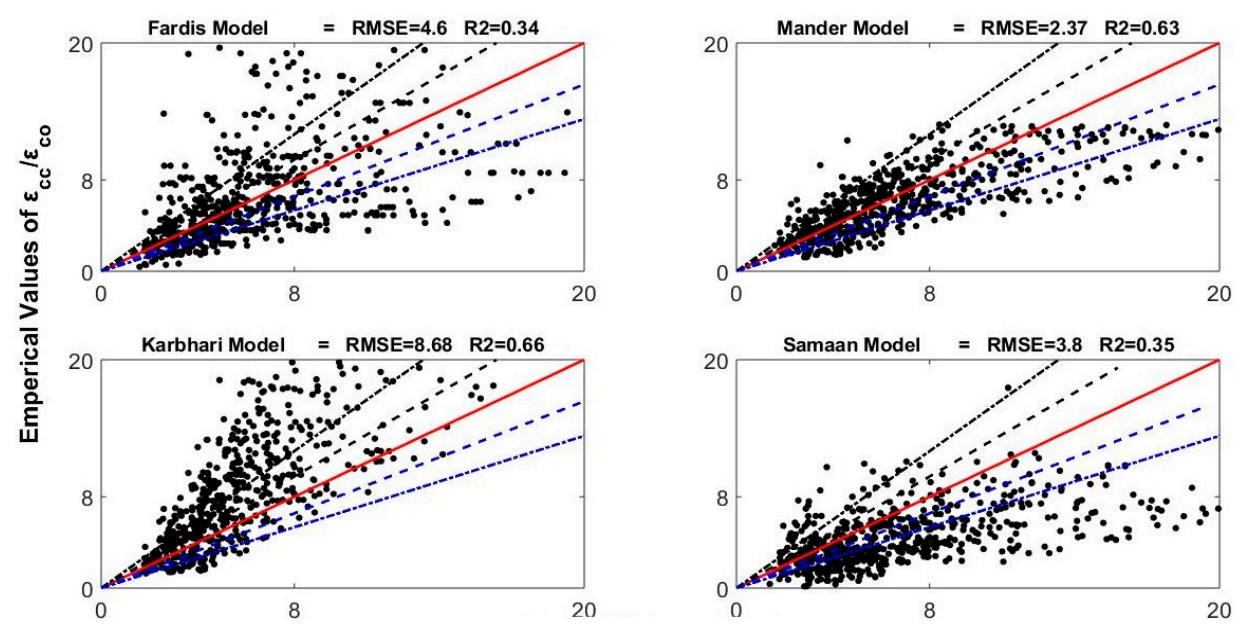

Figure 2. Cont. 


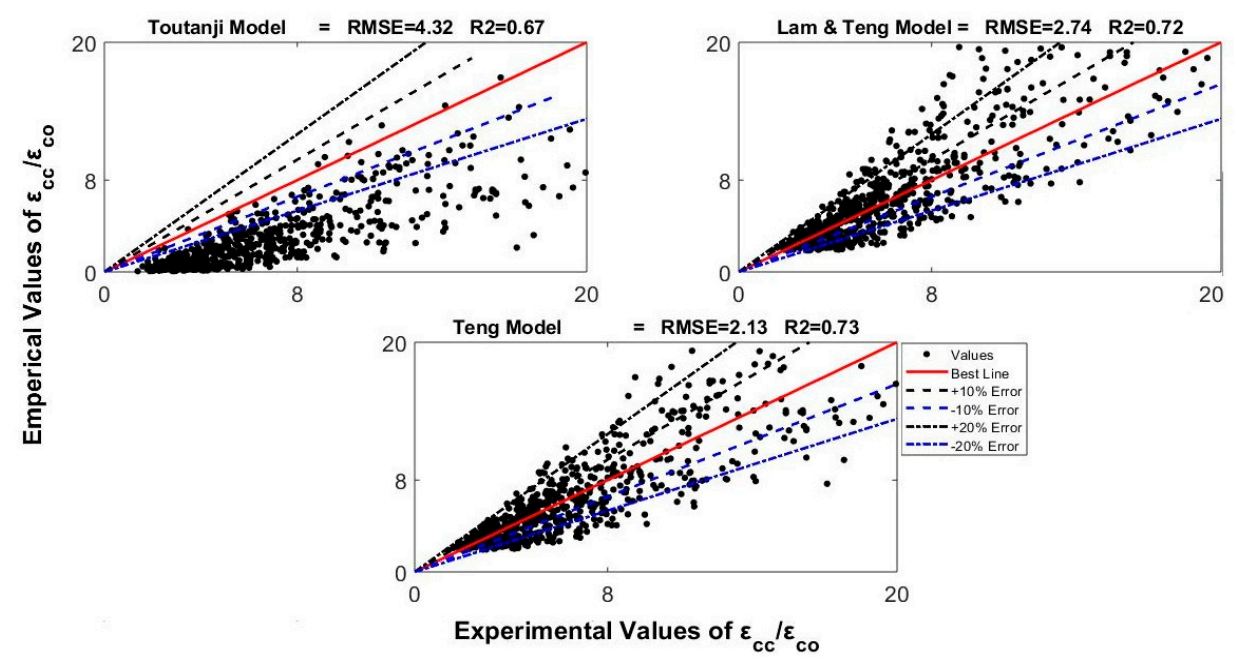

Figure 2. Performance of previously proposed and presently proposed strain models of confined concrete on the developed database.

\subsection{Evaluation of Models}

The strain model proposed by Fardis and Khalili [15] represents the performance on the previous experimental database with $\mathrm{R}^{2}$ of 0.34 and RMSE of 4.6 which tell that the concept behind this model, i.e., the ultimate strain increases with the circumferential stiffness of confined concrete, was not accurate. Mander et al. [16] model shows the performance with $\mathrm{R}^{2}=0.63$ and RMSE $=2.37$ which is a relatively good performance due to which this model was recommended by ACI 440-2R-02 [34]. Similarly, Karbhari and Gao [17] model shows the performance with $R^{2}=0.66$ and $\mathrm{RMSE}=8.68$; Samaan et al. [18] model shows the performance with $R^{2}=0.35$ and RMSE $=3.80$; Toutanji [19] model shows the performance with $\mathrm{R}^{2}=0.67$ and RMSE $=4.32$; Lam and Teng [20] model shows the performance with $\mathrm{R}^{2}=0.72$ and RMSE $=2.74$ and Teng et al. [21] model shows the performance with $R^{2}=0.73$ and $R M S E=2.13$. These evaluations represent that the model proposed by Teng et al. [21] gave the best performance among the evaluated models. The values of $R^{2}$ and RMSE for all the evaluated models were also presented in Table 3. Therefore, the general form of this model was selected as final for the current study as given by Equation (14). After determining the constants of the selected form of strain model, the proposed nonlinear analytical model for strain of FRP confined concrete is given by Equation (15).

$$
\varepsilon_{c c} / \varepsilon_{c o}=\alpha+\beta \rho_{k}^{\lambda_{1}} \rho_{\varepsilon}^{\lambda_{2}}
$$

where $\alpha, \beta, \lambda_{1}$ and $\lambda_{2}$ are constants which were determined by using general regression analysis.

$$
\varepsilon_{c c} / \varepsilon_{c o}=1.85+7.46 \rho_{k}^{0.71} \rho_{\varepsilon}^{1.17}
$$

Table 3. Values of coefficient of determination $\left(R^{2}\right)$ and root mean square error (RMSE) for various previously proposed models on the developed database.

\begin{tabular}{lrr}
\hline \multicolumn{1}{c}{ Researcher } & RMSE & \multicolumn{1}{c}{$\mathbf{R}^{\mathbf{2}}$} \\
\hline Fardis and Khalili [15] model & 4.6 & 0.34 \\
Mander et al. [16] model & 2.37 & 0.63 \\
Karbhari and Gao [17] model & 8.68 & 0.66 \\
Samaan et al. [18] model & 3.8 & 0.35 \\
Toutanji [19] model & 4.32 & 0.67 \\
Lam and Teng [20] model & 2.74 & 0.72 \\
Teng et al. [21] model & 2.13 & 0.73 \\
Proposed model & 1.93 & 0.74 \\
\hline
\end{tabular}


The performance of the proposed analytical strain model is given in Figure 3 using the database of 678 points with the $\mathrm{R}^{2}=0.74$ and $\mathrm{RMSE}=1.93$. These statistical indices show that the performance of currently proposed strain model is better than that of the previously proposed models with significant accuracy because the index of RMSE is less and index of $\mathrm{R}^{2}$ is higher for the proposed model which is desirable.

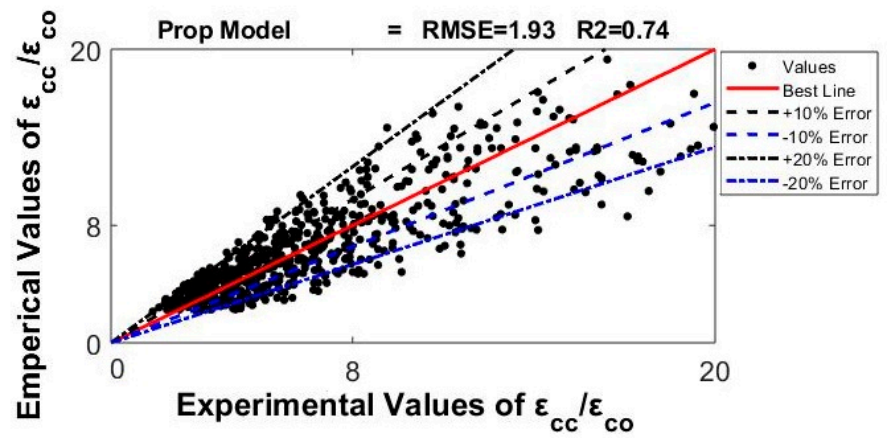

Figure 3. Performance of proposed empirical models of confined concrete.

For a comparative study of the currently proposed and previously proposed strain models, the normal distribution curves and ratios of predictions were plotted. The normal distribution of confined concrete strains to unconfined concrete strains ratios of experimental predictions to theoretical predictions of different models for the previous database were presented by Figure 4 and the distribution of confined concrete strains to unconfined concrete strains ratios of the database was presented by Figure 5. The proposed analytical model and Lam and Teng [20] model performed well for the mean normalized values. The deviations of the proposed analytical model and Lam and Teng [20] model were $2.5 \%$ and $3 \%$ from unity, respectively. The normalized predictions of other previously proposed strain models were found to be conservative. It was observed that Toutanji [19] model presented most of $\varepsilon_{c c} / \varepsilon_{c o}$ ratios in the range $0.0-2.0$. Thus, the proposed strain models for confined concrete are capable of providing the accurate results for confined concrete strain as compared with previous models.

A general flow chart of the present work has been shown in Figure 6. A large experimental database of confined concrete strains was collected from literature and some preliminary evaluations were made on it using statistical indices such as $\mathrm{R}^{2}$, SSE, and RMSE. The analytical model was proposed using curve fittings in MATLAB by minimizing the error functions and by determining the constants.

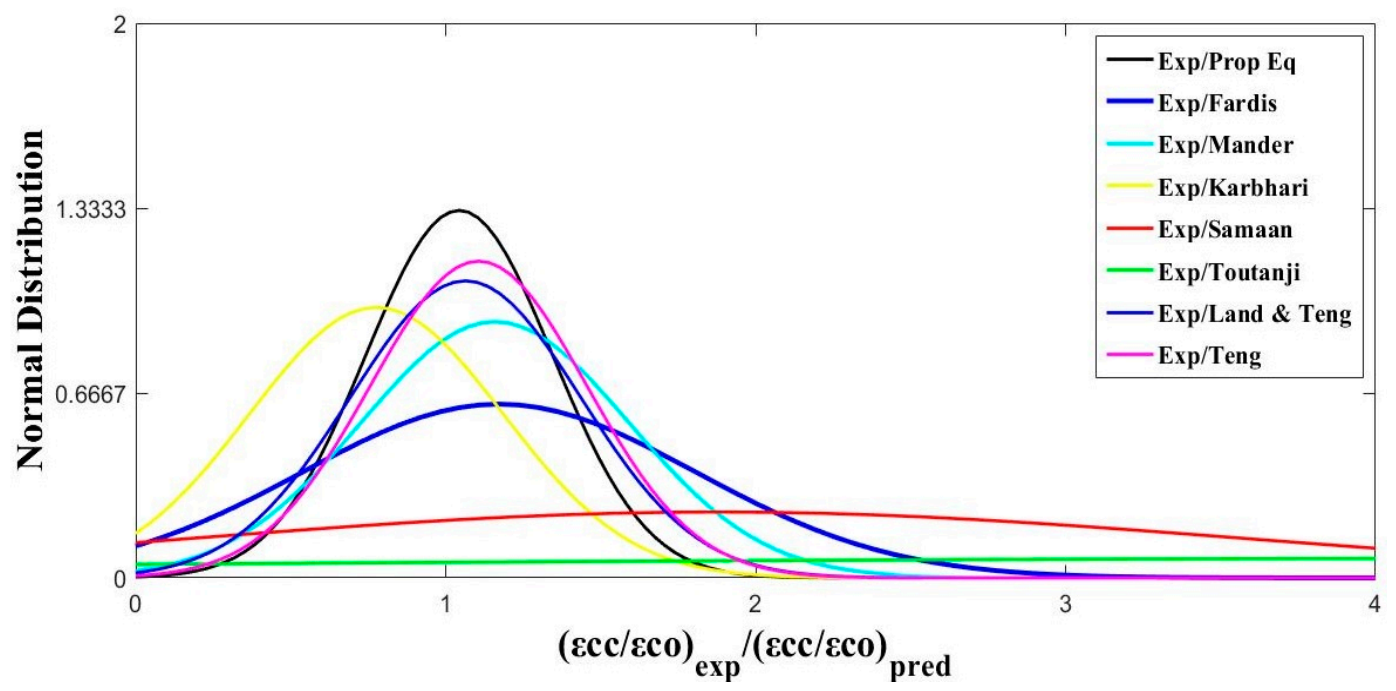

Figure 4. Normal distribution of $\left(\varepsilon_{c c} / \varepsilon_{c o e x p}\right) /\left(\varepsilon_{c c} / \varepsilon_{c o p r e d}\right)$ for FRP-wrapped cylinders based on predictions of various strain models. 


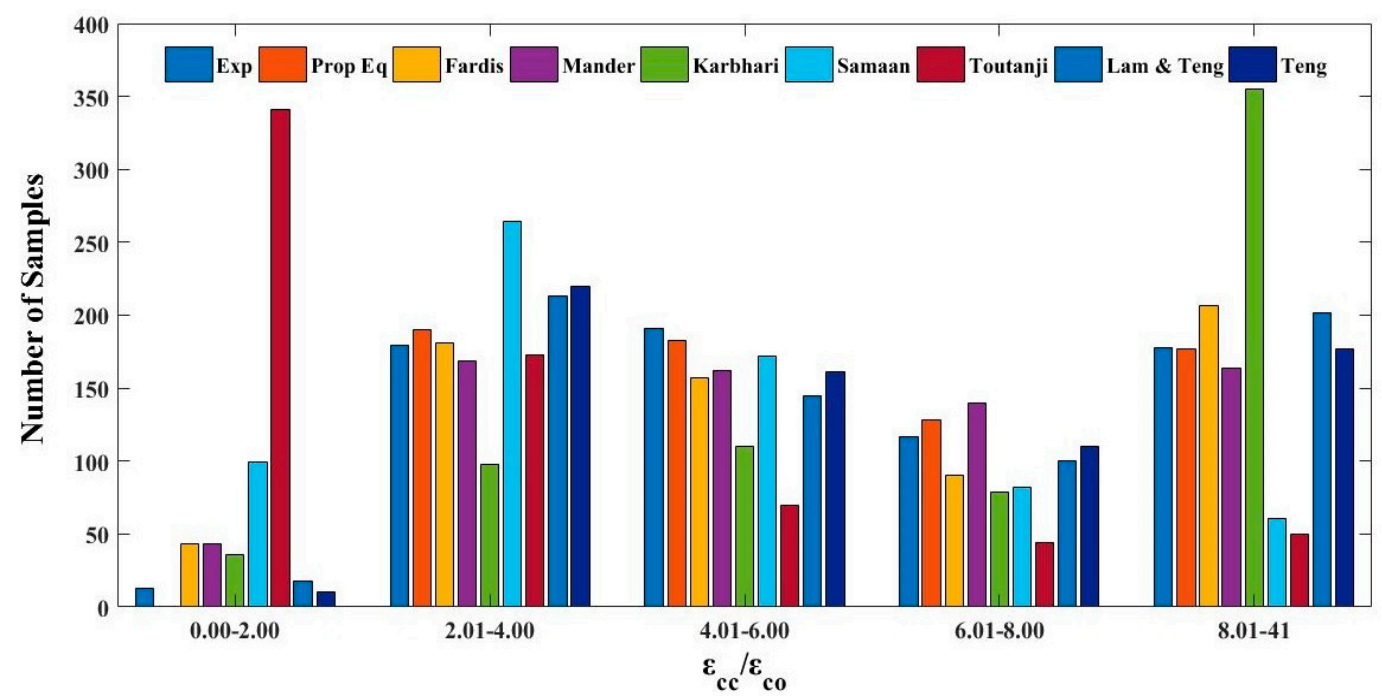

Figure 5. Distribution of $\varepsilon_{c c} / \varepsilon_{c o}$ for FRP-wrapped cylinders based on predictions of various strain models.

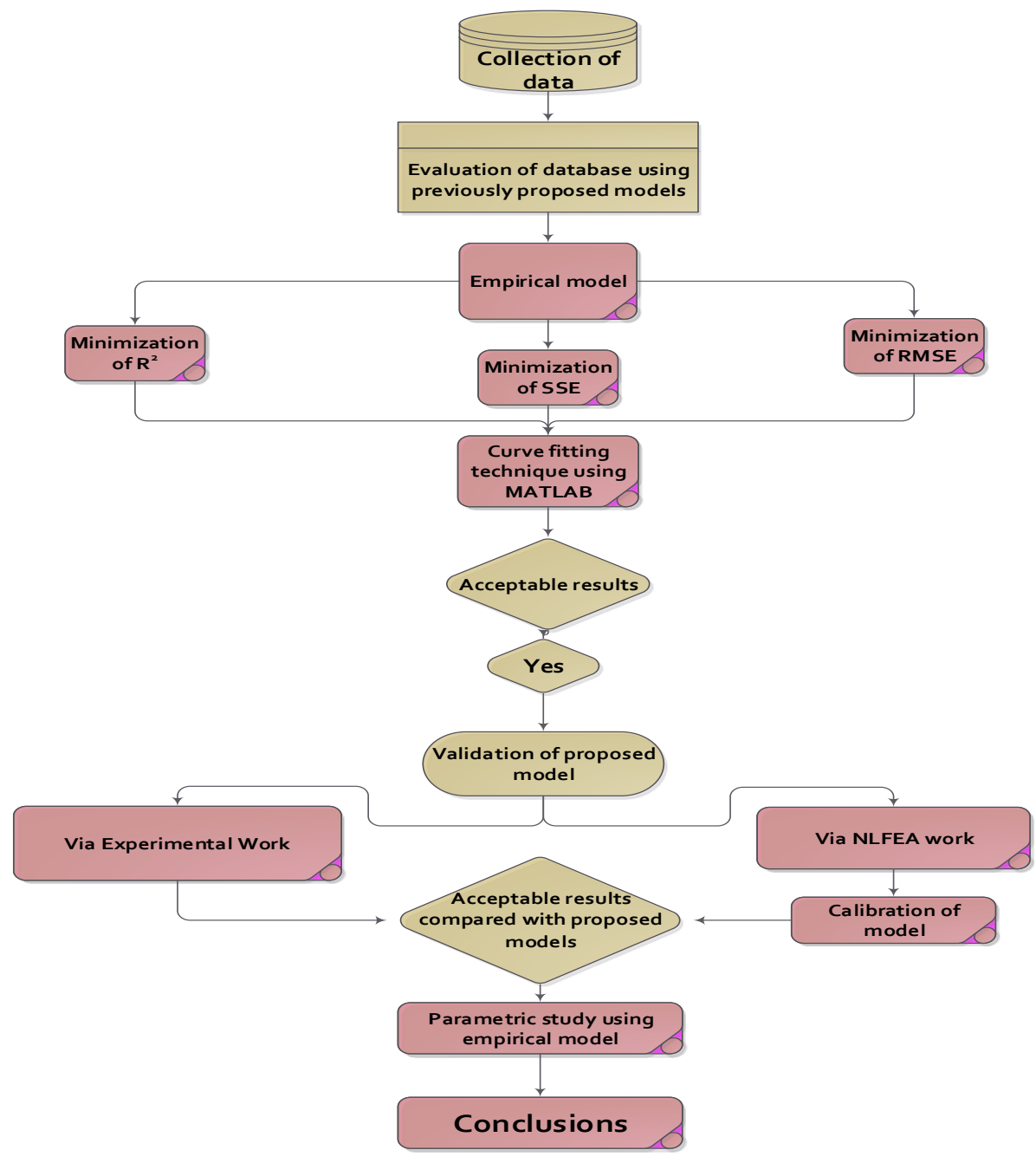

Figure 6. Flow chart of the present research work. 


\section{Validation of Proposed Empirical Model}

For the validation of proposed strain models, a nonlinear FEA work was performed for FRP confined concrete cylinders. The predictions of FEA model were compared with currently proposed and previous strain models.

\subsection{Nonlinear Finite Element Analysis (NLFEA)}

Numerical methods are more efficient and economical tools as compared with experiments for the structural analysis and engineering research [26]. These methods can save the cost and time by developing the numerical models that can capture the complex damage behavior accurately. The finite element modelling of cylinders confined with FRPs was done using the commercial software ABAQUS (version 6.14, Simulia corp., Providence, U.S, 2013). The results of proposed model were validated using the load-deflection curves from the literature [35]. A control cylinder was used to propose a numerical model after the calibration of different parameters such as dilation angle, viscosity parameter of concrete, mesh size and element types of the concrete. The behavior of concrete was simulated by using concrete damaged plasticity (CDP) model and FRP wraps were simulated using Hashin's damage model $[36,37]$. To define the contact between concrete column and FRP sheets, a perfect bond was defined by applying "tie" constraint between them. The accurate definition of the bonding behavior between the FRP sheets and concrete is very important for the precise predictions [38,39]. The boundary conditions and meshing used in the numerical model of cylinder were presented in Figure 7. The bottom end of cylinders was fixed for displacements and rotations in all directions and displacement control technique was used for the application of load on the top surface. During the calibration process of finite element model, the default values for shape factor $K c=0.667$, for eccentricity $=0.1$ and for compressive stresses ratios $=1.16$ were taken to define the plastic behavior of concrete in ABAQUS. The compressive behavior as shown in Figure 8a, was used for concrete in the present study. The linear elastic behavior of concrete may be taken up to $0.4 f_{c m}$ [40]. The relations proposed by [41] were used to find the average compressive strain $\varepsilon_{c 1}$ and the ultimate strain $\varepsilon_{c u 1}$ of the concrete as presented by Equations (16) and (17).

$$
\begin{aligned}
& \varepsilon_{c 1}=0.0014\left[2-e^{-0.024 f_{c m}}-e^{-0.140 f_{c m}}\right] \\
& \varepsilon_{c u 1}=0.004-0.0011\left[1-e^{-0.0215} f_{c m}\right]
\end{aligned}
$$

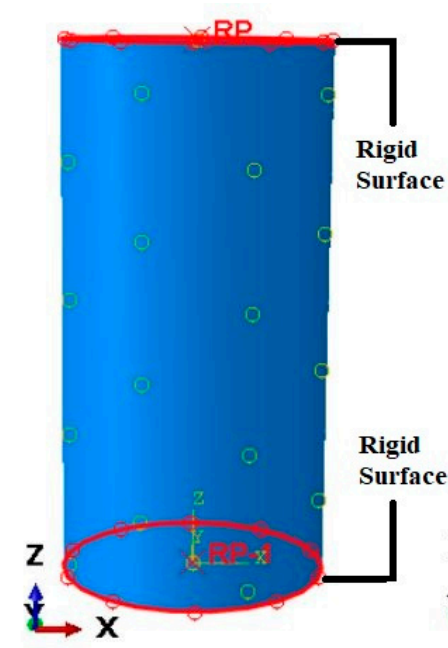

(a)

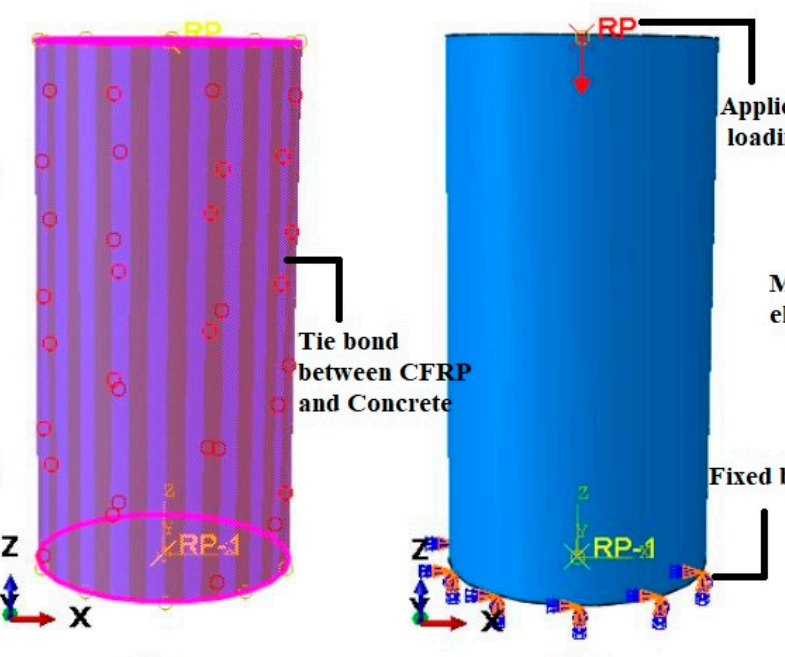

(b)

(c)

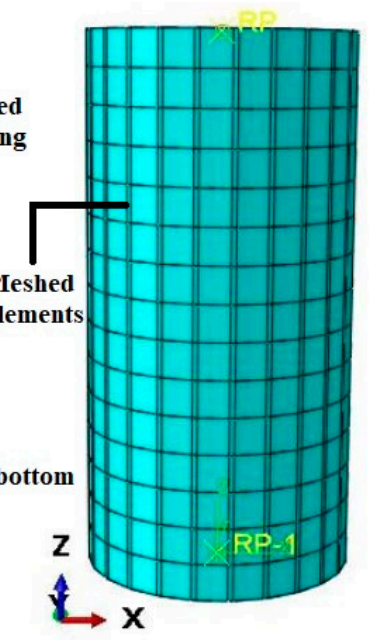

(d)

Figure 7. Geometry and boundary conditions of cylinders: (a) rigid body surfaces, (b) tie constraint between FRP and concrete, (c) loading and boundary conditions, (d) meshing. 


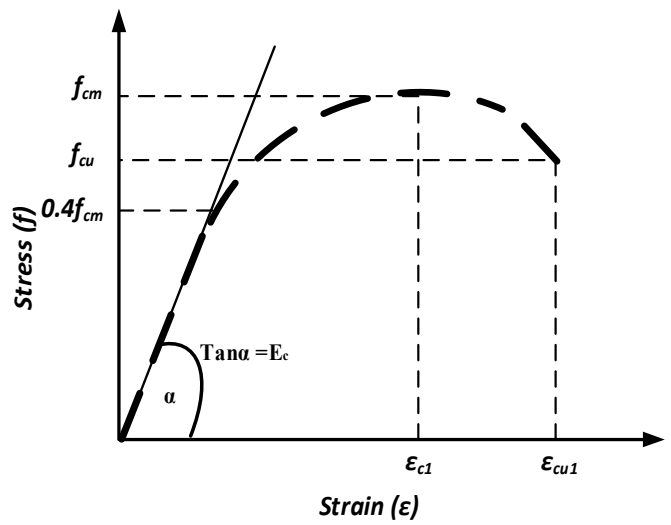

(a)

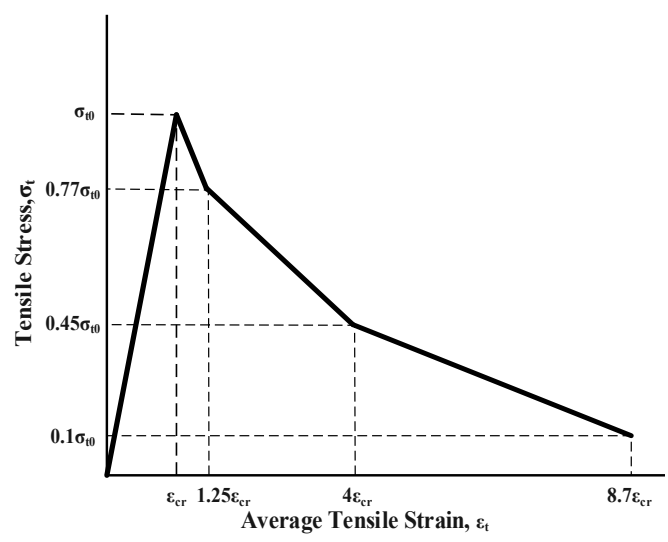

(b)

Figure 8. (a) Stress-strain curve for reinforced concrete given by Euro code [42] and (b) modified tension stiffening model.

To define the stress-strain relationship of concrete, the model given by Eurocode [42] was used given by Equation (18).

$$
\sigma_{c}=f_{c m} \frac{k \eta-\eta^{2}}{1+(k-2) \eta}
$$

where,

$$
k=1.05 E_{c m} \frac{\varepsilon_{c 1}}{f_{c m}}, \eta=\frac{\varepsilon_{c}}{\varepsilon_{c 1}}
$$

The tensile behavior of concrete was defined by modified tension stiffening model [43] (see Figure $8 b$ ).

A control model was selected for the calibration purpose having a single layer of FRP material with compressive strength of $12.5 \mathrm{MPa}$. Firstly, the selected concrete cylinder was calibrated to achieve a reliable finite element model (FEM) in which the numerical results of stress-strain are in close agreement with experimental results and then, this calibrated model was utilized for the simulations of all FRP-wrapped cylinders. Various viscosity parameters of $0.00001,0.0010,0.0030,0.0055,0.0070$, 0.0090 and 0.0110 were studied to predict the effect of this parameter on the stress-strain behavior of concrete. A viscosity parameter of 0.0055 gave the best approximation for the stress-strain behavior of plain concrete and hence, this value was selected for the viscosity parameter of concrete in the current work.

The effect of dilation angle, viscosity parameter and mesh size of concrete are shown in Figure 9. The experimental peak value of stress was $12.5 \mathrm{MPa}$ at a strain of 0.0017 . From the first subplot of Figure 9, it can be examined that the peak stress value matches the experimental value when the values of the viscosity parameter and dilation angle are 0.0055 and $30^{\circ}$, respectively. For dilation angle, the Drucker-Prager plastic potential function was used as given by Equation (20).

$$
G(\sigma)=\sqrt{\left(\varepsilon \sigma_{\text {to }} \tan \psi\right)^{2}+\bar{q}^{2}}+\frac{1}{3} I_{1} \tan \psi
$$

where, $\alpha_{p}$ is the dilatancy parameter according to Lee and Fenves [44] having a value of 0.2 , for which the dilation angle should be near to $30^{\circ}$. After the calibration for dilation angle of concrete, the value of $30^{\circ}$ gave the best approximation as compared with the previous experimental stress-strain results of the control specimen. 


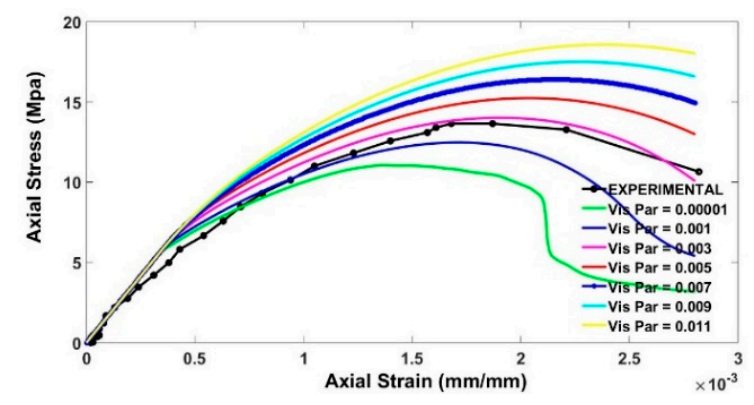

(a)

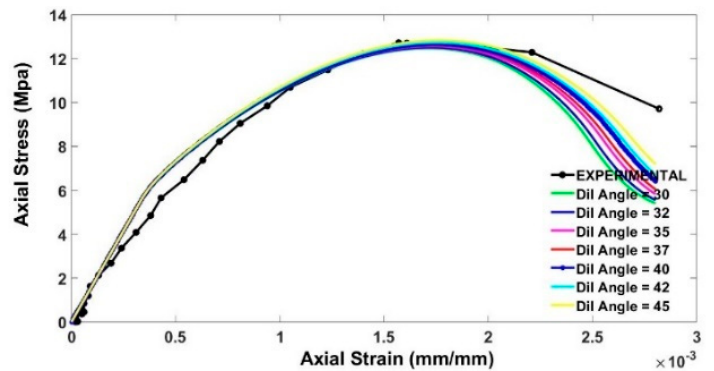

(b)

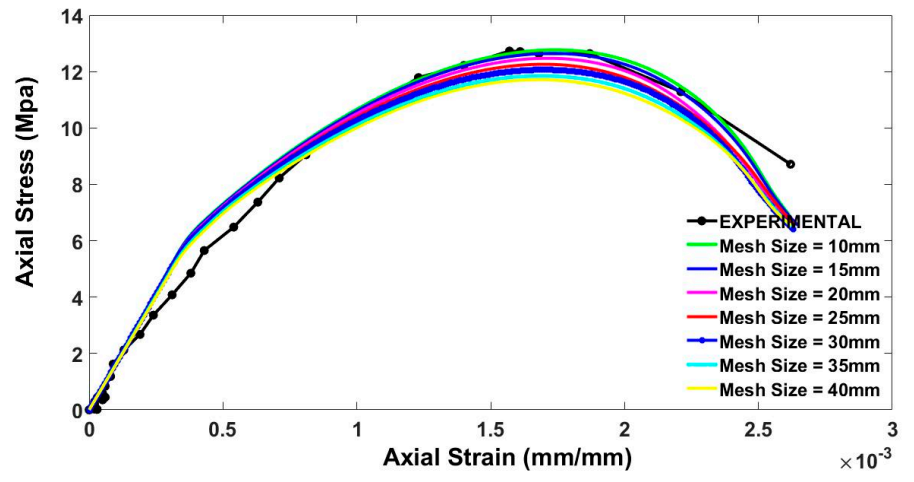

(c)

Figure 9. Effect of (a) viscosity parameter, (b) dilation angle and (c) mesh size on stress-strain behavior of control cylinder specimen (C12.5-1L).

The numerical model of the control cylinder presented here is highly depending upon the mesh size because of the strain localization phenomena. To achieve better results of control specimen in terms of load-deflection curve, it is important to use smaller mesh size but not enough smaller to enhance the analysis time and burden of computer to solve the equations formed by the FEA procedure. Different mesh sizes ranging from $10 \mathrm{~mm}$ to $40 \mathrm{~mm}$ were used to see the effect of the variation of the mesh size dependency but found better results at mesh size of $20 \mathrm{~mm}$. From Figure 9, a close agreement with experimental stress was achieved when the mesh size of $20 \mathrm{~mm}$ was used with the viscosity parameter of 0.0055 and dilation angle of $30^{\circ}$. Similarly, it can be observed that the strain of 0.0017 was achieved by using viscosity parameter, dilation angle and mesh size of $0.0055,30^{\circ}$ and $20 \mathrm{~mm}$ at the same time, respectively.

The influence variation of stress ratio, eccentricity and shape factor for the plastic behavior of concrete in CDP model was also investigated but their effect on stress-strain behavior of cylinders was negligible. Thus, the default values, i.e., $K_{c}=0.667, \varepsilon=0.1$ and $\sigma_{b 0} / \sigma_{c 0}=1.16$ were used. The effect of different element types of concrete was also studied in this research. All the element library of ABAQUS for the 3D stress elements of concrete was studied to check the effects of elements types of concrete. The hexahedral, tetrahedral and triangular elements with different formulations were analyzed giving the best approximate at C3D8R elements.

For the simulations of FRP sheets, the Hashin damage model was used. The FRP material can be considered as a 2D filament object having different moduli of elasticity in longitudinal and transverse directions and its behavior can be defined by two stages: the first is elastic stage defined by modulus of elasticity and Poisson's ratio as shown in Table 4 and the second is the plastic stage which is defined by Hashin's [37] failure model. ABAQUS Standard follows the Hashin's theory [36,37] for the prediction of damage criterion of FRPs using four damage mechanisms which are fiber tension and compression and matrix tension and compression. The failure of FRP resulting due to shear can be defined by Equation (21) as presented by [45]:

$$
\gamma_{x y}=G_{x y}^{-1} \sigma_{x y}+\alpha \sigma_{x y}^{3}
$$


where, $\gamma_{x y}$ is shear strain in x-y plain, $G_{x y}$ is the shear modulus of elasticity of FRP and $\alpha$ is the nonlinearity factor having a value of $55 \times 10^{-5} \mathrm{MPa}^{-3}$. The different variables for the Hashin damage model are given in Table 5. The strength properties in the transverse direction were taken as small values compared with the properties in longitudinal direction [30].

Table 4. Elastic behavior of FRP.

\begin{tabular}{lc}
\hline \multicolumn{1}{c}{ Property } & Value \\
\hline Longitudinal modulus of elasticity, $E_{1}(\mathrm{GPa})$ & 230 \\
Transverse modulus of elasticity, $E_{2}(\mathrm{GPa})$ & 16.583 \\
Longitudinal-transverse Poisson's ratio, $v_{12}$ & 0.3 \\
Shear moduli $G_{12}, G_{13}, G_{23}(\mathrm{MPa})$ & $9188.5,12259,5911$ \\
\hline
\end{tabular}

Table 5. Damage variables of Hashin's Model.

\begin{tabular}{ll}
\hline \multicolumn{1}{c}{ Property } & Value \\
\hline Tensile strength in fiber dir. (MPa) & 3900 \\
Compressive strength in fiber dir. (MPa) & 3120 \\
Tensile strength in transverse dir. (MPa) & 210.6 \\
Compressive strength in transverse dir. (MPa) & 643.5 \\
Shear Strength in longitudinal dir. (MPa) & 210.6 \\
Shear Strength in transverse dir. (MPa) & 276.9 \\
\hline
\end{tabular}

\subsection{Discussion of Results}

Figure 10 shows the compressive strengths and strains of unconfined and confined concrete cylinders tested in the previous study [35]. The average stress-strain curves of experimental cylinders were plotted against the FEA results.
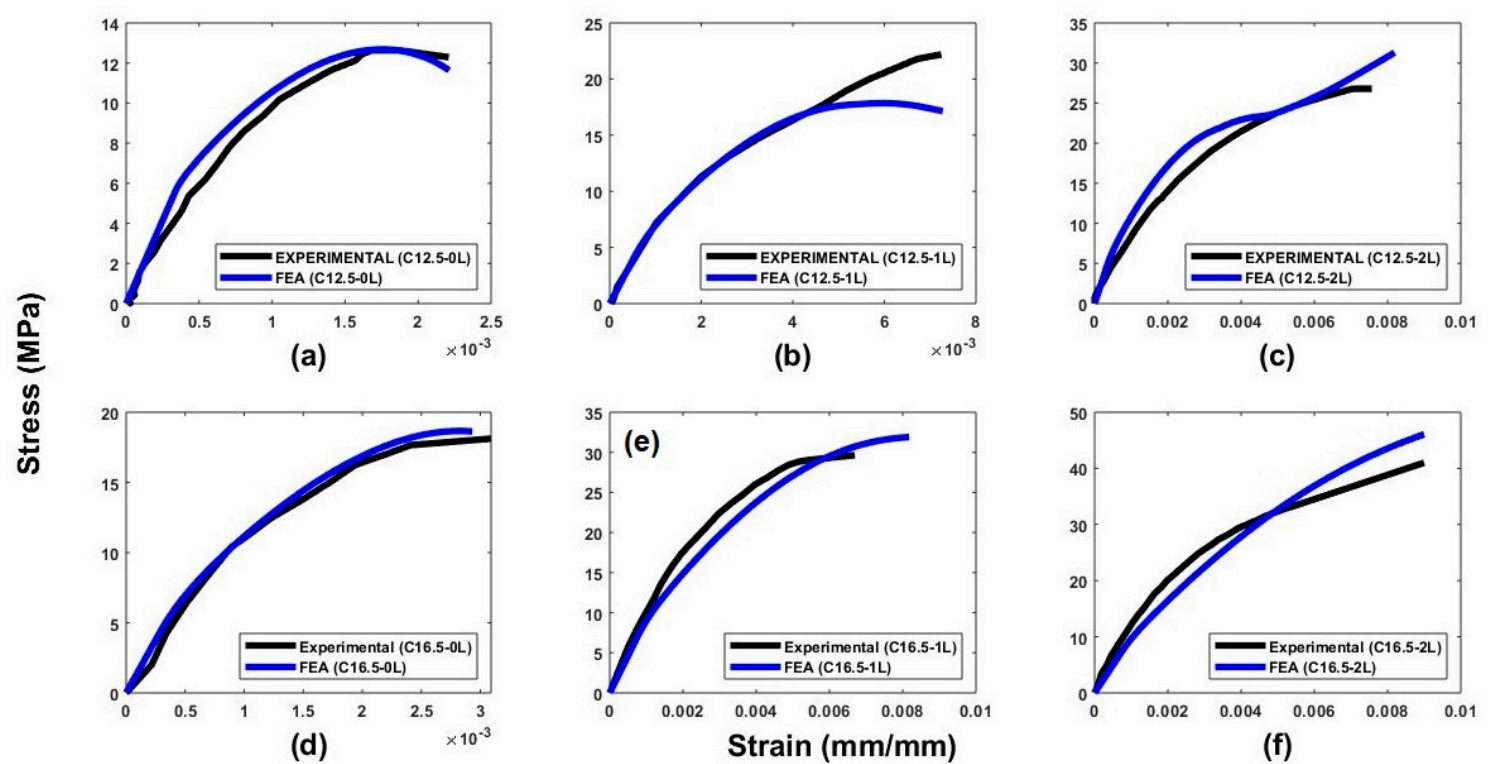

(c)
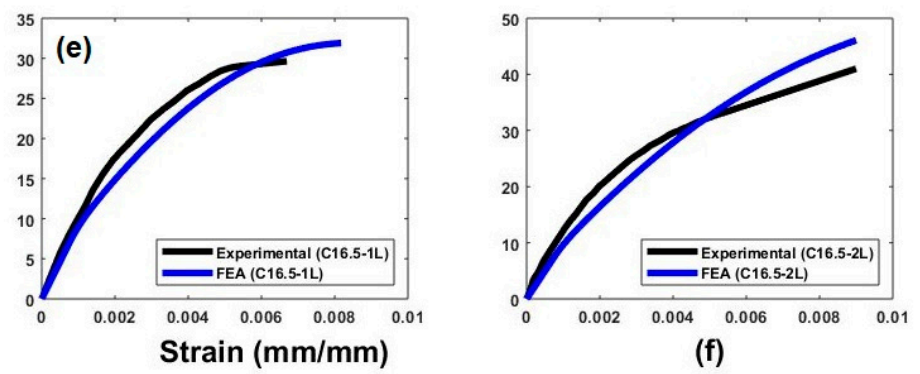

Figure 10. Stress-strain curves of (a) unconfined concrete cylinder and (b-f) confined concrete cylinders.

The experimental results confirmed the increase in strength and ductility with the increasing number of FRP layers. It was observed that the increase of $69.42 \%$ and $87.20 \%$ occurred in axial strength of confined concrete of $12.5 \mathrm{MPa}$ strength for single and double wraps of FRP, respectively and an increase of $60.82 \%$ and $103.20 \%$ occurred for $16.5 \mathrm{MPa}$ concrete with single and double wraps of FRP, respectively as compared with plain concrete specimens. Similarly, the axial strain of cylinders was increased by $409.26 \%$ and $277.78 \%$ using single layer of FRP and $464.81 \%$ and $459.72 \%$ using double 
layer of FRP with 12.5 MPa and 16.5 MPa, respectively. This discussion shows that the confinement is effective in low strength concrete for both strength and ductility of concrete.

The average percentage discrepancies between the experimental and FEA results of FRP confined concrete cylinders were $14.93 \%$ and $16.93 \%$ for axial strength and axial strain, respectively. These discrepancies may be due to the minor inaccuracies due to the difference between actual and testing and boundary conditions, assumptions made during FEA and the accuracy of the testing instruments. However, the overall experimental stress-strain curves of all the cylinders were predicted accurately by the FEA results showing that the selected constitutive FEA model can be utilized for the simulations of FRP-confined concrete.

The crack patterns of some specimens obtained from FEA results are shown in Figure 11. The finite element crack patterns were represented through maximum principal plastic strains because the concrete damaged plasticity model (CDPM) assumes that the cracks in the concrete start when there is a positive value of maximum principal plastic strain. The FEA cracks in concrete can also be represented by tensile principal stresses [2,46]. Figure 11 represents the cracking patterns of a plain concrete cylinder, a double-layered FRP cylinder with strength of $12.5 \mathrm{MPa}$ and two cylinders with single and double layers of FRP sheets having the concrete strength of $16.5 \mathrm{MPa}$. It can be visualized that the FEA crack patterns are in a close agreement with the experimental cracks proving that the FEA software ABAQUS accurately predicted the behavior of FRP-wrapped concrete. The FEA cracks decrease with less expansion of concrete cylinders as the confinement thickness increases which is experimentally true.

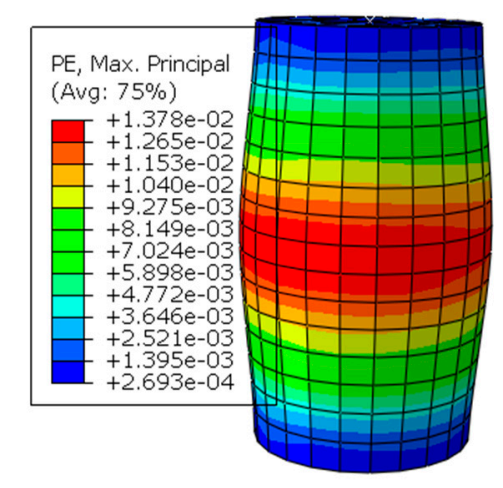

C12.5-0L

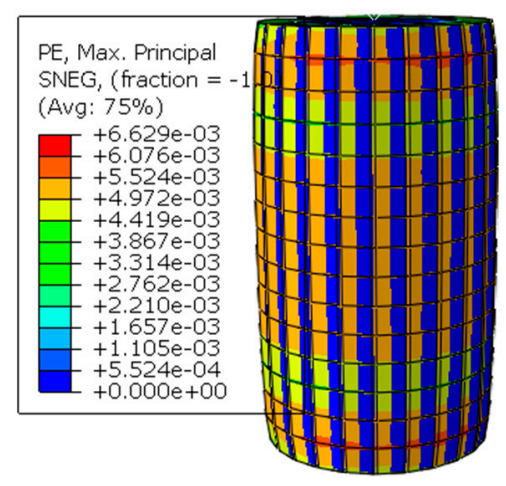

C16.5-1L

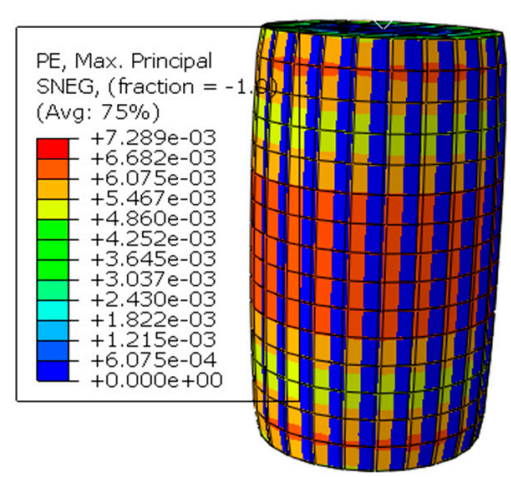

C12.5-2L

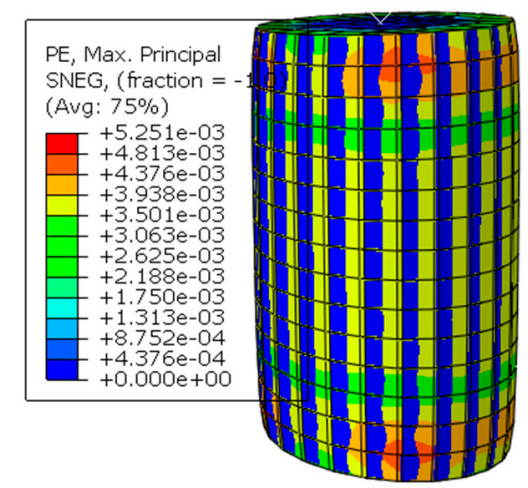

C16.5-2L

Figure 11. Crack patterns of tested specimens in ABAQUS.

The average percentage discrepancies of the predictions of proposed empirical strain model from experimental and FEA results were $13.51 \%$ and $37.81 \%$, respectively, which shows that the proposed model can predict the strain of FRP-confined concrete. All the results for compressive strains 
of confined concrete obtained from previously proposed empirical models, present experimental measurements, numerical and empirical predictions are presented in Figure 12.

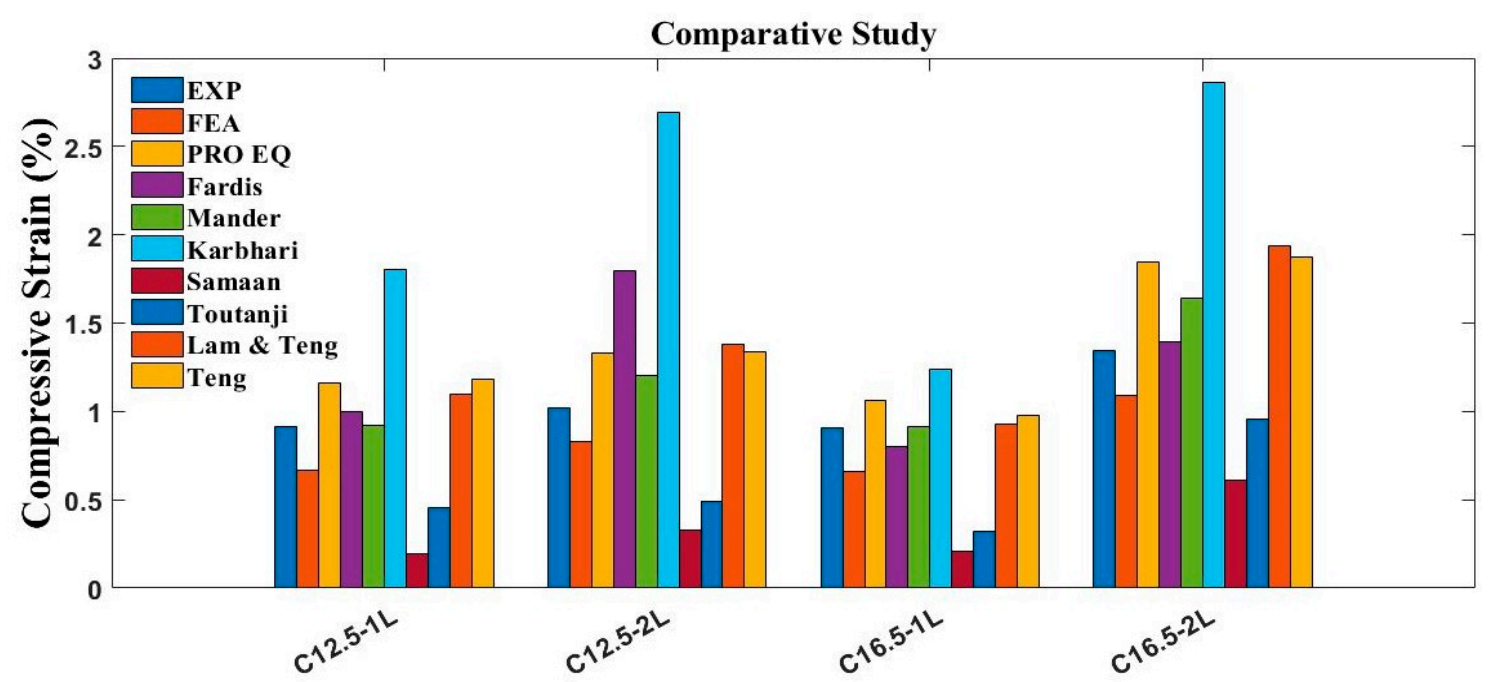

\section{Specimen Label}

Figure 12. Performance of previous and currently proposed strain models on the experimental results of confined concrete cylinders.

The percentage discrepancies of strain models proposed by Fardis and Khalili [15], Mander et al. [16], Karbhari and Gao [17], Samaan et al. [18], Toutanji [19], Lam and Teng [20] and Teng et al. [21] from the experimental results were $25.34 \%, 10.07 \%, 103.01 \%, 3.80 \%, 16.47 \%, 25.61 \%$, and $27.00 \%$, respectively. It can be visualized that the proposed analytical equation is giving more precise predictions in comparison with experiments as discussed in the previous section. The maximum error was represented by Karbhari and Gao [17] model with a discrepancy of $103.01 \%$. This discrepancy may be due to the reason that this model does not capture the true behavior of composite concrete and considers the constant confinement level without confinement jackets. Moreover, this model was proposed on the wrong assumption that the FRP material can reach its maximum tensile strength in the transverse direction.

\section{Parametric Studies}

An extensive parametric study was performed by using the proposed empirical model to investigate the effects of the parameters including (a) unconfined concrete strength, (b) elastic modulus of FRP, (c) diameter of concrete cylinders and (d) total thickness of FRPs layers. For the study of each parameter, the objective is to see the effect of that parameter on axial strain of confined concrete. The constant and varying values of the studied parameters are shown in Table 6. The effect of any two parameters was observed at a time in three-dimensional plots while keeping the other parameters constant as shown in Figure 13.

Table 6. Statistical information of the parameters used in parametric studies.

\begin{tabular}{ccc}
\hline Parameters & Constant Values & \multicolumn{1}{c}{ Varying Values } \\
\hline$D(\mathrm{~mm})$ & 150 & $100,150,200,250,300,350,400,450,500,550$ \\
$n t(\mathrm{~mm})$ & 0.75 & $0.15,0.25,0.35,0.45,0.55,0.65,0.75,0.85,0.95,1.05$ \\
$E_{f}(\mathrm{GPa})$ & 200 & $110,125,140,155,170,185,200,215,230,245$ \\
$f_{c o}(\mathrm{MPa})$ & 25 & $5,10,15,20,25,30,35,40,45,50$ \\
\hline
\end{tabular}



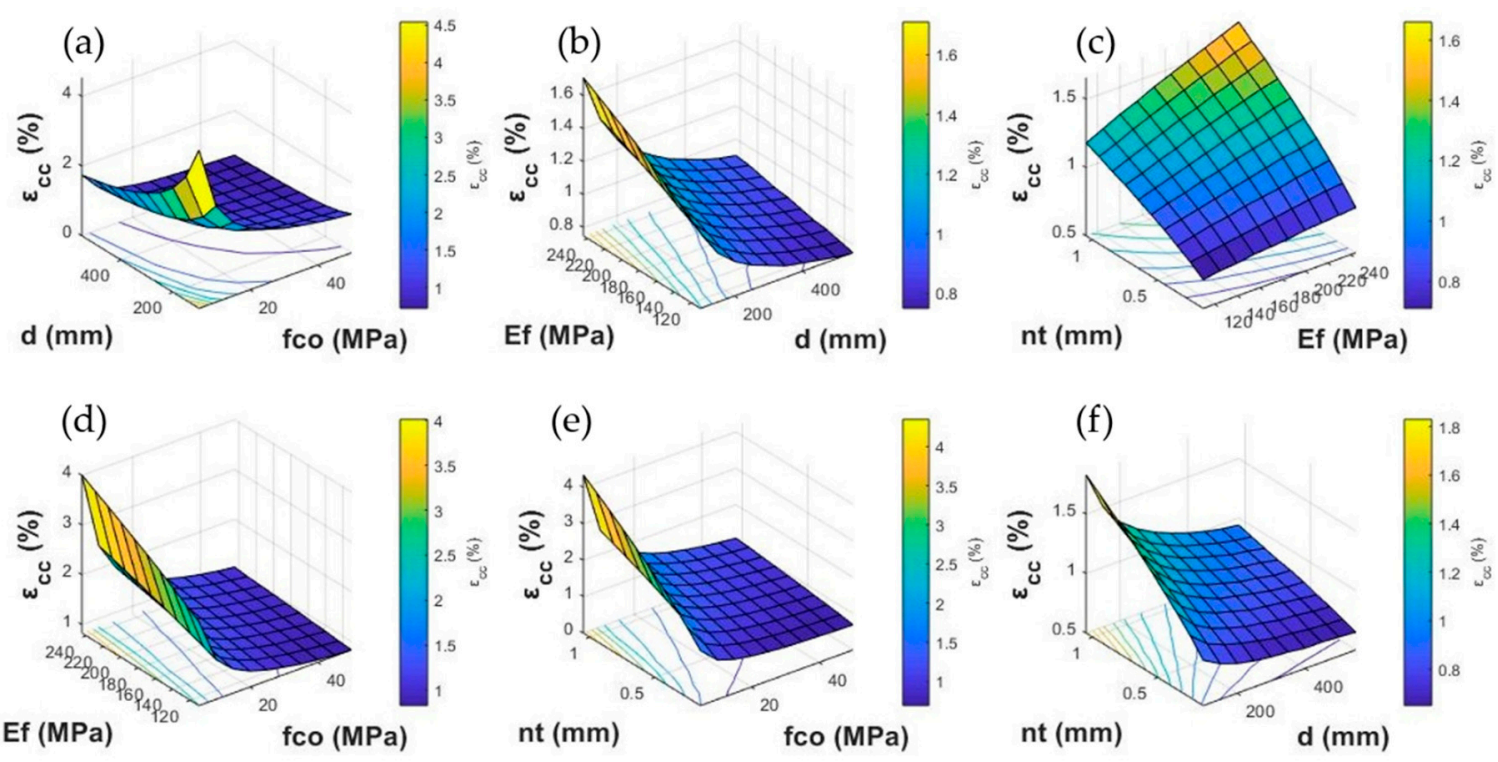

Figure 13. Parametric studies using proposed strain model.

\subsection{Effect of Concrete Compressive Strength $\left(f_{c o}^{\prime}\right)$}

The different values of unconfined concrete strengths $\left(f_{c o}^{\prime}\right)$ being used for the parametric study are $5 \mathrm{MPa}$ to $50 \mathrm{MPa}$ at an increment of $5 \mathrm{MPa}$. The effect of $f_{c o}^{\prime}$ variation is shown in Figure 13a,d,e. It was noted that when $f_{c o}^{\prime}$ increases from $5 \mathrm{MPa}$ to $50 \mathrm{MPa}$ and diameter of cylinder $(d)$ increases from $100 \mathrm{~mm}$ to $550 \mathrm{~mm}$ at constant thickness $(n t)$ and elastic modulus of fibers $\left(E_{f}\right)$, the confined strain $\left(\varepsilon_{c c}\right)$ using the proposed model increases by $84.14 \%$. When the elastic modulus of FRP increases from $110 \mathrm{GPa}$ to $245 \mathrm{GPa}$ at same increment of $f_{c o}^{\prime}$, the $\varepsilon_{c c}$ of concrete increases by $58.57 \%$. Similarly, when the $f_{c o}^{\prime}$ increases from $5 \mathrm{MPa}$ to $50 \mathrm{MPa}$ with the increase of fiber thickness from $0.15 \mathrm{~mm}$ to $1.05 \mathrm{~mm}$, an increase of $28.48 \%$ takes place in the $\varepsilon_{c c}$. This section shows that the effect of increment of $f_{c o}^{\prime}$ is more dominant when the diameter of specimen is increased. The hoop rupture strain of cylinders was determined using Equation (4) [33].

\subsection{Effect of Cylinder Diameter (d)}

The diameters of concrete cylinders used for the parametric study are from $100 \mathrm{~mm}$ to $550 \mathrm{~mm}$ at an increment of $50 \mathrm{~mm}$. The variation of $\varepsilon_{c c}$ due to the increase of concrete diameter $(d)$ is presented in Figure $13 \mathrm{a}, \mathrm{b}, \mathrm{f}$. It can be observed that the $\varepsilon_{c c}$ of concrete increases up to $84.14 \%$ when $f_{c o}^{\prime}$ increases from $5 \mathrm{MPa}$ to $50 \mathrm{Mpa}$ and d increases from $100 \mathrm{~mm}$ to $550 \mathrm{~mm}$ at constant $E_{f}$ and $n t$. When $d$ increases from $100 \mathrm{~mm}$ to $550 \mathrm{~mm}$ with an increase of $E_{f}$ from $110 \mathrm{GPa}$ to $245 \mathrm{Gpa}$, the decrement of $25.62 \%$ occurred in $\varepsilon_{c c}$. Therefore, it can be visualized that at lower diameters, the effect of $E_{f}$ on $\varepsilon_{c c}$ is significant. Similarly, when the thickness of FRP increases from $0.15 \mathrm{~mm}$ to $1.05 \mathrm{~mm}$ at the same increase of $d$, an increase of only $6.82 \%$ occurred. However, at lower $d$, the effect of increasing the thickness of FRP is more significant.

\subsection{Effect of Elastic Modulus of FRP ( $\left.E_{f}\right)$}

The effect of variations of $E_{f}$ is shown in Figure $13 \mathrm{~b}-\mathrm{d}$. The different values used for the $E_{f}$ are $110 \mathrm{GPa}$ to $245 \mathrm{GPa}$ at an increment of $15 \mathrm{GPa}$. When the $E_{f}$ increases from $110 \mathrm{GPa}$ to $245 \mathrm{GPa}$ with an increase of $d$ from $100 \mathrm{~mm}$ to $550 \mathrm{~mm}, \varepsilon_{c c}$ increases by $25.62 \%$. Similarly, when $E_{f}$ increases from $110 \mathrm{GPa}$ to $245 \mathrm{GPa}$ and thickness of FRP increases from $0.15 \mathrm{~mm}$ to $1.05 \mathrm{~mm}$, the increment in $\varepsilon_{c c}$ was $133.80 \%$. The combined effect of $E_{f}$ and $f_{c o}^{\prime}$ was shown in Figure 13d, which represents that the increase of $58.57 \%$ occurred due to increase of $E_{f}$ from initial to final value with an increase of $50 \mathrm{MPa}$ in $f_{c o}^{\prime}$. This study concludes that the effect of increment of $E_{f}$ is more significant for $\varepsilon_{\mathcal{c} c}$ with the increase of $n t$. 


\subsection{Effect of Thickness of FRP Layers (nt)}

The range of thickness of FRP layers was $0.15 \mathrm{~mm}$ to $1.05 \mathrm{~mm}$ at an increment of $0.10 \mathrm{~mm}$. The effect of variations of thickness of FRP layers is shown in Figure 13c,e,f. When $n t$ increases from $0.15 \mathrm{~mm}$ to $1.05 \mathrm{~mm}$ and $E_{f}$ increases from $110 \mathrm{GPa}$ to $245 \mathrm{GPa}$, the increment in $\varepsilon_{c c}$ was up to $133.80 \%$. When $n t$ increases from $0.15 \mathrm{~mm}$ to $1.05 \mathrm{~mm}$ with an increase of $50 \mathrm{MPa}$ in $f_{c o}^{\prime}, 28.48 \%$ increase in the $\varepsilon_{c c}$ occurred showing that the effect of increasing the $n t$ is more significant at higher values of $f_{c o}^{\prime}$. Similarly, the effect of increasing the $n t$ at larger diameters of concrete was negligible, but at lower values of diameter, the effect of increment of $n t$ on $\varepsilon_{c c}$ was significant as presented in Figure 13f.

In general, by increasing the unconfined concrete strength $\left(f_{c o}^{\prime}\right)$, the confined concrete strain $\left(\varepsilon_{c c}\right)$ increases slightly and by increasing the thickness of FRP $(n t)$, there is a significant increase in $\varepsilon_{c c}$. Similarly, the effect of the increase of elastic modulus of FRP $\left(E_{f}\right)$ on $\varepsilon_{c c}$ is significant. However, the effect of increasing the diameter of concrete $(d)$ was opposite. At lower values of diameter, the value of $\varepsilon_{c c}$ was higher.

\section{Conclusions}

The present study aims to evaluate the effectiveness and reliability of FRP wrapping on plain concrete and to propose the FEA and empirical models for predicting the axial compressive strain of FRP confined concrete. The main conclusions derived from the present study work are as given:

- The proposed analytical strain model performed well in the previous experimental database of 678 samples with $\mathrm{R}^{2}=0.74$ and RMSE $=1.93$. Thus, the performance of proposed model on the previous experimental database shows its superiority over the previous models.

- The FEA performed in the present study shows that the average percentage discrepancies between previous experimental and current FEA results for FRP confined concrete cylinders were 14.93\% and $13.88 \%$ for strength and strain, respectively. It shows that the finite element (FE) model traced the experimental behavior of FRP-confined concrete accurately.

- The average percentage discrepancy for axial strain between the previous experimental and proposed empirical model results was only $13.51 \%$. Similarly, the average percentage discrepancy for axial strain between present NLFEA and proposed empirical model results was only $37.81 \%$. Thus, the proposed empirical model for confined concrete strains was in a close agreement for performance with the experimental and NLFEA results.

- The parametric study using the proposed empirical model concluded that the axial confined strain of concrete increases with the increase of unconfined strength and thickness of FRP layers and its elastic modulus, while no significant effect was observed for increasing the core diameter of concrete.

- From the comparisons of this study, it can be concluded that the proposed empirical and FEA models can predict the axial strain of FRP-confined concrete with accuracy and are helpful for engineers in analyzing and designing the FRP-confined concrete compression members.

Author Contributions: Conceptualization, A.R. and S.A.R.S.; formal analysis, A.R.K.; methodology, A.R., M.A.A. and T.A.K.; validation, S.H., A.S. and K.A.; visualization, A.R.K.; writing-original draft, A.R. and S.A.R.S.; writing-review and editing, G.S. and M.W. All authors have read and agreed to the published version of the manuscript.

Funding: This research received no external funding.

Conflicts of Interest: The authors declare no conflict of interest.

\section{References}

1. Hollaway, L.C.; Chryssanthopoulos, M.; Moy, S.S. Advanced Polymer Composites for Structural Applications in Construction: ACIC 2004; Woodhead Publishing: Sawston, UK, 2004; Volume 1, pp. 771-772. 
2. Raza, A.; Khan, Q.U.Z.; Ahmad, A. Numerical investigation of load-carrying capacity of GFRP-reinforced rectangular concrete members using CDP model in ABAQUS. Adv. Civ. Eng. 2019, 2019. [CrossRef]

3. Parvin, A.; Jamwal, A.S. Effects of wrap thickness and ply configuration on composite-confined concrete cylinders. Compos. Struct. 2005, 67, 437-442. [CrossRef]

4. Li, G.; Kidane, S.; Pang, S.-S.; Helms, J.E.; Stubblefield, M.A. Investigation into FRP repaired RC columns. Compos. Struct. 2003, 62, 83-89. [CrossRef]

5. Demers, M.; Neale, K.W. Confinement of reinforced concrete columns with fibre-reinforced composite sheets-an experimental study. Can. J. Civ. Eng. 1999, 26, 226-241. [CrossRef]

6. Prota, A.; Manfredi, G.; Cosenza, E. Ultimate behavior of axially loaded RC wall-like columns confined with GFRP. Compos. B Eng. 2006, 37, 670-678. [CrossRef]

7. Li, L.J.; Guo, Y.C.; Liu, F.; Bungey, J.H. An experimental and numerical study of the effect of thickness and length of CFRP on performance of repaired reinforced concrete beams. Constr. Build. Mater. 2006, 20, 901-909. [CrossRef]

8. Li, G.; Maricherla, D.; Singh, K.; Pang, S.S.; John, M. Effect of fiber orientation on the structural behavior of FRP wrapped concrete cylinders. Compos. Struct. 2006, 74, 475-483. [CrossRef]

9. Ţăranu, N.; Oprişan, G.; Enţuc, I.; Munteanu, V.; Cozmanciuc, C. The Efficiency of Fiber Reinforced Polymer Composites Solutions in the Construction Industry. In Proceedings of the 6th International Conference on Management of Technological Changes, MTC, Alexandroupolis, Greece, January 2009; pp. 733-736.

10. De Lorenzis, L.; Tepfers, R. Comparative study of models on confinement of concrete cylinders with fiber-reinforced polymer composites. J. Compos. Constr. 2003, 7, 219-237. [CrossRef]

11. Kawashima, K.; Koyama, T. Effects of cyclic loding hysteresis on dynamic behavior of reinforced concrete bridge piers. Doboku Gakkai Ronbunshu 1988, 1988, 139-146. [CrossRef]

12. Hoshikuma, J.; Kawashima, K.; Nagaya, K.; Taylor, A.W. Stress-strain model for confined reinforced concrete in bridge piers. J. Struct. Eng.-Asce. 1997, 123, 624-633. [CrossRef]

13. Kawashima, K.; Shoji, G.; Sakakibara, Y. A cyclic loading test for clarifying the plastic hinge length of reinforced concrete piers. J. Struct. Eng.-Asce. 2000, 46, 767-776.

14. Ann, K.; Cho, C.-G. Constitutive behavior and finite element analysis of FRP composite and concrete members. Materials 2013, 6, 3978-3988. [CrossRef] [PubMed]

15. Fardis, M.N.; Khalili, H.H. FRP-encased concrete as a structural material. Mag. Concrete Res. 1982, 34, 191-202. [CrossRef]

16. Mander, J.B.; Priestley, M.J.; Park, R. Theoretical stress-strain model for confined concrete. J. Struct. Eng.-Asce. 1988, 114, 1804-1826. [CrossRef]

17. Karbhari, V.M.; Gao, Y. Composite jacketed concrete under uniaxial compression-Verification of simple design equations. J. Mater. Civ. Eng. 1997, 9, 185-193. [CrossRef]

18. Samaan, M.; Mirmiran, A.; Shahawy, M. Model of concrete confined by fiber composites. J. Struct. Eng.-Asce. 1998, 124, 1025-1031. [CrossRef]

19. Toutanji, H. Stress-strain characteristics of concrete columns externally confined with advanced fiber composite sheets. ACI Mater. J. 1999, 96, 397-404.

20. Lam, L.; Teng, J. Design-oriented stress-strain model for FRP-confined concrete. Constr. Build. Mater. 2003, 17, 471-489. [CrossRef]

21. Teng, J.G.; Yu, T.; Wong, Y.L.; Dong, S.L. Hybrid FRP-concrete-steel tubular columns: Concept and behavior. Constr. Build. Mater. 2007, 21, 846-854. [CrossRef]

22. Miyauchi, K.; Inoue, S.; Kuroda, T.; Kobayashi, A. Strengthening effects of concrete column with carbon fiber sheet. Trans. Jpn. Concr. Inst. 2000, 21, 143-150.

23. Bisby, L.A.; Dent, A.J.S.; Green, M.F. Comparison of confinement models for fiber-reinforced polymer-wrapped concrete. ACI Struct. J. 2005, 102, 62-72.

24. Matthys, S.; Toutanji, H.; Audenaert, K.; Taerwe, L. Axial load behavior of large-scale columns confined with fiber-reinforced polymer composites. ACI Struct. J. 2005, 102, 258.

25. Shi, Y.; Swait, T.; Soutis, C. Modelling damage evolution in composite laminates subjected to low velocity impact. Compos. Struct. 2012, 94, 2902-2913. [CrossRef]

26. Matthews, F.L.; Davies, G.; Hitchings, D.; Soutis, C. Finite Element Modelling of Composite Materials and Structures; CRC Press: Boston, MA, USA; New York, NY, USA; Washington, DC, USA, 2000; pp. 1-52. 
27. Ribeiro, F.; Sena-Cruz, J.; Branco, F.G.; Júlio, E. 3D finite element model for hybrid FRP-confined concrete in compression using modified CDPM. Eng. Struct. 2019, 190, 459-479. [CrossRef]

28. Piscesa, B.; Attard, M.M.; Samani, A.K. 3D Finite element modeling of circular reinforced concrete columns confined with FRP using a plasticity based formulation. Compos. Struct. 2018, 194, 478-493. [CrossRef]

29. Lo, S.; Kwan, A.K.H.; Ouyang, Y.; Ho, J.C.M. Finite element analysis of axially loaded FRP-confined rectangular concrete columns. Eng. Struct. 2015, 100, 253-263. [CrossRef]

30. Hany, N.F.; Hantouche, E.G.; Harajli, M.H. Finite element modeling of FRP-confined concrete using modified concrete damaged plasticity. Eng. Struct. 2016, 125, 1-14. [CrossRef]

31. Ferrotto, M.; Fischer, O.; Cavaleri, L. A strategy for the finite element modeling of FRP-confined concrete columns subjected to preload. Eng. Struct. 2018, 173, 1054-1067. [CrossRef]

32. Teng, J.G.; Jiang, T.; Lam, L.; Luo, Y.Z. Refinement of a design-oriented stress-strain model for FRP-confined concrete. J. Compos. Constr. 2009, 13, 269-278. [CrossRef]

33. Lim, J.C.; Karakus, M.; Ozbakkaloglu, T. Evaluation of ultimate conditions of FRP-confined concrete columns using genetic programming. Comput. Struct. 2016, 162, 28-37. [CrossRef]

34. Bakis, C.E.; Ganjehlou, A.; Kachlakev, D.I.; Schupack, M.; Balaguru, P.N.; Gee, D.J.; Karbhari, V.M.; Scott, D.W.; Ballinger, C.A.; Gentry, T.R.; et al. Guide for the design and construction of externally bonded FRP systems for strengthening concrete structures. ACI Committee Rep. 2002, 440.2R-1-440.2R-45.

35. Saeed, H.Z.; Khan, Q.U.Z.; Khan, H.A.; Farooq, R. Experimental investigation of stress-strain behavior of CFRP confined Low Strength Concrete (LSC) cylinders. Constr. Build. Mater. 2016, 104, 208-215. [CrossRef]

36. Hashin, Z.; Rotem, A. A fatigue failure criterion for fiber reinforced materials. J. Compos. Mater. 1973, 7, 448-464. [CrossRef]

37. Hashin, Z. Failure criteria for unidirectional fiber composites. J. Appl. Mech. 1980, 47, 329-334. [CrossRef]

38. Cascardi, A.; Micelli, F.; Aiello, M.A. Unified model for hollow columns externally confined by FRP. Eng. Struct. 2016, 111, 119-130. [CrossRef]

39. Monaldo, E.; Nerilli, F.; Vairo, G. Effectiveness of some technical standards for debonding analysis in FRP-concrete systems. Compos. B Eng. 2019, 160, 254-267. [CrossRef]

40. Kmiecik, P.; Kamiński, M. Modelling of reinforced concrete structures and composite structures with concrete strength degradation taken into consideration. Arch. Civ. Mech. Eng. 2011, 11, 623-636. [CrossRef]

41. Majewski, S. The Mechanics of Structural Concrete in Terms of Elasto-Plasticity; Publishing House of Silesian University of Technology: Gliwice, Poland, 2003.

42. De Normalisation, C.E.J.B. Belgium, Eurocode 2: Design of Concrete Structures-Part 1-1: General Rules and Rules for Buildings. 2004. Available online: https:/www.phd.eng.br/wp-content/uploads/2015/12/en. 1992.1.1.2004.pdf (accessed on 31 December 2019).

43. Wahalathantri, B.L.; Thambiratnam, D.P.; Chan, T.H.T.; Fawzia, S. A material model for flexural crack simulation in reinforced concrete elements using ABAQUS. In Proceedings of the First International Conference on Engineering, Designing and Developing the Built Environment for Sustainable Wellbeing, Queensland University of Technology, Brisbane, Australia, April 2011; pp. 260-264.

44. Lee, J.; Fenves, G.L. Plastic-damage model for cyclic loading of concrete structures. J. Eng. Mech. 1998, 124, 892-900. [CrossRef]

45. Lessard, L.B.; Chang, F.K. Damage tolerance of laminated composites containing an open hole and subjected to compressive loadings: Part II-Experiment. J. Compos. Mater. 1991, 25, 44-64. [CrossRef]

46. Genikomsou, A.S.; Polak, M.A. Finite element analysis of punching shear of concrete slabs using damaged plasticity model in ABAQUS. Eng. Struct. 2015, 98, 38-48. [CrossRef]

(C) 2020 by the authors. Licensee MDPI, Basel, Switzerland. This article is an open access article distributed under the terms and conditions of the Creative Commons Attribution (CC BY) license (http://creativecommons.org/licenses/by/4.0/). 